\title{
Comparing different approaches to visualizing light waves: An experimental study on teaching wave optics
}

\author{
Vanes Mešici, ${ }^{1, *}$ Erna Hajder, ${ }^{1}$ Knut Neumann, ${ }^{2}$ and Nataša Erceg ${ }^{3}$ \\ ${ }^{1}$ Faculty of Science, University of Sarajevo, Zmaja od Bosne 33-35, 71000 Sarajevo, \\ Bosnia and Herzegovina \\ ${ }^{2}$ Leibniz Institute for Science and Mathematics Education (IPN) at the University of Kiel, \\ 24118 Kiel, Germany \\ ${ }^{3}$ Department of Physics, University of Rijeka, R. Matejčić 2, 51000 Rijeka, Croatia
}

(Received 17 October 2015; published 10 June 2016)

\begin{abstract}
Research has shown that students have tremendous difficulties developing a qualitative understanding of wave optics, at all educational levels. In this study, we investigate how three different approaches to visualizing light waves affect students' understanding of wave optics. In the first, the conventional, approach light waves are represented by sinusoidal curves. The second teaching approach includes representing light waves by a series of static images, showing the oscillating electric field vectors at characteristic, subsequent instants of time. Within the third approach phasors are used for visualizing light waves. A total of $N=85$ secondary school students were randomly assigned to one of the three teaching approaches, each of which lasted a period of four class hours. Students who learned with phasors and students who learned from the series of static images outperformed the students learning according to the conventional approach, i.e., they showed a much better understanding of basic wave optics, as measured by a conceptual survey administered to the students one week after the treatment. Our results suggest that visualizing light waves with phasors or oscillating electric field vectors is a promising approach to developing a deeper understanding of wave optics for students enrolled in conceptual level physics courses.
\end{abstract}

DOI: 10.1103/PhysRevPhysEducRes.12.010135

\section{INTRODUCTION}

A conceptual understanding of wave optics is a major element of developing competence in physics. Understanding wave optics is, for example, a prerequisite for understanding solid-state physics [1] or quantum mechanics [2]. Wave optics is also important for understanding modern technologies (e.g., holography) and many everyday phenomena (e.g., colored soap bubbles). Physics education research showed repeatedly, however, that even the strongest university students and physics graduates struggle with developing a conceptual understanding of wave optics [2-5]. Although the understanding of wave optics in secondary school students is relatively unexplored, the findings for university samples indicate that learning wave optics is certainly a very problematic endeavor for many secondary school students.

One potential source of students' difficulties in understanding wave optics lies in the fact that wave optics is amongst the most abstract domains of physics [6]. In addition, understanding wave optics phenomena generally requires students to be able to think about spatial features

\footnotetext{
*vanes.mesic@gmail.com

Published by the American Physical Society under the terms of the Creative Commons Attribution 3.0 License. Further distribution of this work must maintain attribution to the author $(s)$ and the published article's title, journal citation, and DOI.
}

(e.g., the oscillatory state depends on the spatial coordinate), as well as temporal features of the wave (e.g., the oscillatory state depends on the time passed). This need for simultaneous spatiotemporal processing is particular challenging to students in their learning about wave optics [7]. An additional pedagogical obstacle for developing the understanding of wave optics in the secondary school context is related to the fact that students' level of mathematical skills is relatively low compared to the skills of university students.

Previous research suggests that a conceptual understanding of physics is closely associated with the development of visual mental representations [8]. The development of visual mental representations in turn can be supported through external visualizations $[9,10]$. Thus, visualizations hold the potential to reduce the abstractness of the wave concept and help students to develop a conceptual understanding of wave optics.

We can conclude that in the secondary school context there is a need for an approach that could facilitate the development of relatively deep ideas about wave optics, whereby resorting to sophisticated mathematical apparatus would be replaced by visualizations. In this study we aimed to compare the efficacy of different approaches to visualizing light waves for the development of a conceptual understanding of basic wave optics. From a literature review we identified three approaches to visualizing light waves in the teaching about basic wave optics phenomena, 
such as light interference and diffraction. In the conventional teaching (CT) approach the light waves are represented by means of sinusoidal curves and reasoning about superposition of light waves is based on "adding multiple curves." The sequences of electric vectors (SEV) approach utilizes oscillating electric field vectors to represent light waves and reasoning about superposition of light waves is based on "adding vectors." Finally, the phasor $(P)$ approach builds on phasor diagrams, whereby reasoning about superposition of light waves is also based on "adding vectors."

In a randomized experimental study with $N=85$ students from a secondary school in Bosnia and Herzegovina, we investigated how these three approaches to visualizing light waves compare to each other with respect to helping students develop a deeper understanding of basic wave optics. As such, this study adds to the knowledge of the field in that (a) it examines how a conceptual level wave optics course can help even secondary school students to develop a conceptual understanding of wave optics and by (b) providing evidence about what type of visualizations can best support students in developing this kind of understanding.

\section{THEORETICAL BACKGROUND}

In order to develop competence in science, students need to develop a deep understanding of the core concepts of physics [11]. One such concept is the concept of waves. As a matter of fact, according to Knight [7], waves represent one of the two most important models of classical physics. Furthermore, a good understanding of the wave model facilitates learning of modern physics $[1,7,12,13]$. One of the physics topics that includes learning about waves is wave optics.

\section{A. Research on learning and teaching wave optics}

Our review of relevant literature showed that there is an asymmetry when it comes to the extent to which teaching and learning of wave optics has been researched at various educational levels. There are many more studies that are based on university samples than studies based on secondary school or high school samples. However, according to Wandersee, Mintzes, and Novak [14], most often students' misconceptions are not dependent on the age variable, which means that the results obtained for university samples are relevant for our study, too.

\section{Secondary school students' understanding of wave optics}

In the studies by Hubber [15] and Watts [16], the students' general conceptions or mental models about light were investigated. Watts [16] concluded that for the development of the wave model of light at a more advanced level, it is important that students come to perceive light as something that exists in space apart from its sources and effects. Hubber [15] investigated how students' mental models about light change as a result of teaching physical optics with quantum ideas. It has been found that before starting to formally learn about wave optics, students often think that rays are actual constituents of light. As a result of being taught about wave optics with quantum ideas, most students developed hybrid models that represent a combination of particle and wave scientific models. An interesting finding from the study by Hubber [15] is that students prefer different models of light when approaching different phenomena, and they often do not sufficiently understand the mere nature and function of scientific models.

\section{University students' understanding of wave optics}

Probably the most comprehensive studies, so far, on students' difficulties in learning wave optics have been conducted by the Washington Physics Education Research (PER) group [2,17]. In one of these studies, Ambrose et al. [2] identified three types of student difficulties in wave optics: (1) misapplication of geometrical and wave optics (e.g., students falsely applying geometrical optics concepts to wave optics problems), (2) lack of a qualitative understanding of the wave model (e.g., students failing to understand key concepts about waves, such as path length or phase difference), and (3) difficulties with modern physics concepts (e.g., students believing photons are moving along sinusoidal paths). These findings are supported by the more recent literature on students' understanding of wave optics $[3,5,18]$.

In the study by Maurines [4], it has been shown that students reason about light diffraction at a macroscopic level, following the rays of the incident light, "instead of reasoning at an elementary waves level in using the phase concept and the Huygens-Fresnel principle" (p. 1895). Maurines [4] also found that some students believe that it is possible to obtain an interference pattern even if there is only one point source of light, and that light bends only on the edges of the slit. Coetzee and Imenda [5] found that many first-year university students erroneously think that the superposition of waves also includes a "superposition of wavelengths," whereby the resulting wave has a longer wavelength compared to the individual waves. Further, it has been found that some students perceive interference as a phenomenon in which waves average out, whereas other students erroneously believe that identical waves cancel out as a result of propagating towards each other, due to the misconception that waves act like particles. Finally, in the same study, it was shown that for many students the meaning of waves "being in phase" or "out of phase" is not clear. Sengoren [18] reports the students' mistaken belief that all wave dimensions reduce when wavelength is reduced. Further, she has found that students who demonstrate a wave model by drawing spherical waves (rather than sinusoidal waves) use the wave model more 
functionally. An interesting finding from the study by Sengoren [18] is also related to the fact that students often do not realize that there is a continuity of brightness in interference patterns.

Some assert that potential sources of students' difficulties to comprehend wave optics are related to the necessity of visualizing the wave behavior represented by functions of two variables [7], as well as to the necessity of approximating and extreme case reasoning $[19,20]$.

One additional source of the described students' difficulties could be related to their low level of relevant representational knowledge. As a matter of fact, it has been revealed that students exhibit many difficulties in interpreting various representations of waves and that at least some of the learning difficulties in wave optics originate from students' limited ability of modeling light as an electromagnetic wave [17].

The disconnectedness between scientific models (or theories) of light and the nature of their presentation in conventional approaches to teaching optics was also considered to be one of the factors hindering students' development of an understanding of wave optics by Sengoren [18].

Colombo, Jaen, and de Cudmani [6] recognized the practice of oversimplifying the wave optics subject matter as counterproductive. In addition, Colombo et al. [6] listed the following potential sources of students' difficulties in understanding wave optics: (a) the absence of intuitive models developed from prior experience (unlike in mechanics, cf. Ref. [21]), (b) the practice of teaching interference, diffraction, and polarization as mutually isolated entities.

\section{Research-based approaches to developing students' understanding of wave optics}

Multiple ideas have been developed in the past to improve the teaching of wave optics with the aim to provide students with an adequate model of the wave nature of light and thus enhance their understanding of wave optics $[3,4,18,22]$.

Wosilait et al. [22] designed a tutorial that consists of a carefully prepared set of activities that are directly related to overcoming common student difficulties in learning about double-slit interference, multiple-slit interference, singleslit diffraction, and combined interference and diffraction. The tutorial makes intensive use of the analogy between water waves and light waves, which is introduced in order to develop students' intuitive understanding about fundamental wave concepts, and to provide them with a productive context for developing the ability to reason about spatial and temporal features of the wave. Thereby, the observable macroscopic features of the wave phenomena are linked to the microscopic features of the wave through hands-on work with transparencies that contain visualizations of wave fronts or sinusoidal waves, depending on the specific learning goal.

Maurines [4] agreed with most of the recommendations made by Wosilait et al. [22] and additionally stressed the importance of reconstructing the macroscopic wave from the elementary waves level by applying the Huygens principle qualitatively. This approach is supposed to allow students to relate the elementary waves level at which the teaching focuses with the macroscopic level which is close to the students' common sense reasoning. Sengoren [18] continues the discussion about the use of wave front representations and sinusoidal waves for linking macroscopic and microscopic features of the wave. She advocates the practice of drawing wave surfaces, as well as lines that illustrate the direction of the wave propagation, when introducing phenomena such as refraction, diffraction, and interference. However, Sengoren [18] argues against representing wave propagation from the source (to the screen) via sinusoidal waves, and emphasizes the importance of drawing wave fronts between the slit mask and the screen.

When it comes to understanding wave propagation within the context of wave optics, Colin and Viennot [3] emphasize the importance of using the technique of "backward selection of paths of light." Concretely, after having determined the waves' arrival point on the screen, students should "look backwards" to know which "paths to select and how this selection works" (p. 41). The application of this technique should be followed by "establishing a relation between the meaning of paths of light, the meaning of the lighting of the screen, and the meaning of the sources" (p. 43).

Stefanel, Michelini, and Santi [23] described a modeling approach to learning about single-slit diffraction at secondary school level, whereby students first analyze the diffraction pattern qualitatively before measuring light intensity versus position and fitting the obtained experimental data to a model.

All these suggestions are valuable ideas of how the teaching of wave optics can be improved. However, none of them provide us with practical tools for visualization of the abstract processes that are responsible for the macroscopic features of the wave phenomena (e.g., observable interference patterns) and that can be consistently applied throughout many different wave optics contexts. As a matter of fact, when there is no association of phenomena with (micro)processes that underlie these phenomena, a consistent picture of the phenomena is usually lacking [24]. Further improvement of wave optics instruction could also be potentially achieved by using external visualizations that more effectively direct the students to make inferences [25]. Below, we stress the importance of reasoning about these mechanisms and provide suggestions about effective ways for facilitating internal visualizations of these mechanisms. 


\section{B. Developing students' conceptual understanding of wave optics: A model for conceptual level physics courses}

\section{Key aspects of students' conceptual understanding of wave optics}

According to Ford [26] "conceptual understanding is that which permits one to transfer the explanation of a phenomenon to different variations of a situation that have been already analyzed, and can be proof of the ability of any learner to grasp the concepts of scientific phenomena" (p. 18). Similarly, Michael and Modell [27] state that "understanding is demonstrated when the student is able to predict what will happen in a particular system when the system is perturbed and provide an appropriate explanation for the prediction" (p. 21).

Translated to the context of basic wave optics, we could generally say that conceptual understanding is demonstrated whenever students are able to explain wave optics phenomena which exhibit certain variations compared to originally analyzed wave optics phenomena. Specifically, in introductory physics the demonstration of conceptual understanding of wave optics is very often related to predicting the change in the appearance of the interference pattern, when the corresponding experimental setup is perturbed.

In order to be able to predict or explain light interference patterns, the students have to reason about the irradiance at different points of the screen. The irradiance is proportional to the square of the amplitude of the resultant wave. Consequently, for reasoning about the irradiance of the screen it is of central importance to find the resultant wave that is obtained by addition of individual waves. It can be shown that for coherent waves the amplitude of the resultant wave depends on the amplitudes of the individual waves and their phase differences. Thinking about phase differences between two or more light waves at a certain point of space boils down to identifying the differences between the oscillatory states of these waves' electric field vectors, at that point of space. The phase difference between two or more waves at a certain point of space can be related to different optical path lengths of the waves (i.e., different distances from sources of the waves to the observed point of space, in the given media), as well as to different frequencies and initial phases (i.e., initial oscillatory states) of the waves. Finally, one should note that in most practical contexts determining the phase difference between coherent, interfering light waves boils down to using a simple formula that relates path length difference to phase difference.

After we have gained information about the phase difference between interfering waves, we can proceed to adding these waves. However, reasoning about superposition of multiple waves with arbitrary phase difference is extremely difficult, when it is not supported by use of external representations. On the one hand, it includes the need to think about abstract entities such as waves. On the other hand, it also includes the need for reasoning about multiple entities (i.e., multiple waves) and their abstract, mutual relationships (i.e., phase differences between waves), which potentially results with cognitive overload. One approach to adding waves in order to obtain information about the resultant wave at an arbitrary point of the screen would be to use trigonometric representations of light waves. However, these representations are usually considered to be too complex and abstract for teaching wave optics at the secondary school level. Besides that, generally it seems that relying on propositional representations only is a practice that hinders the development of qualitative understanding of physics (see Ref. [8]). One potential option for facilitating the development of deep conceptual understanding of wave optics is related to the use of external visualizations.

\section{Visualizations as a means to develop conceptual understanding of wave optics}

At the heart of developing physics understanding is the process of constructing effective internal representations of physical systems $[8,10]$. This process can be facilitated by the use of external representations $[9,28,29]$. Generally, representations can be defined as any notation or sign or set of symbols which "re-presents"-both external and internally-something to us in the absence of that thing (Ref. [30], p. 202). Visualizations can be considered to be one type of external representations [10] and they can be defined as "any visual-spatial display in which information is communicated by the spatial arrangement of elements in the representation" (Ref. [31], p. 40). Visualizations potentially facilitate the development of physics understanding by [10] (a) conveying abstract information, (b) identifying elements that are key to understanding the underlying physics concepts, and (c) acting as a simulation that students can manipulate in order to test hypotheses and solve problems (which is at the heart of the abduction processes as described by Clement and Steinberg [32]).

That external representations (and particularly visualizations) can facilitate the development of students' understanding is today commonplace [33]. However, it is important to note that the effectiveness of visualizations in physics teaching largely depends on whether the mental activity required by visualization-based tasks effectively enables the construction of internal representations [10]. As a matter of fact, Geelan, Mukharjee, and Martin [34] showed that using visualizations for teaching Newton's first law, accelerated motion and momentum, is not associated with better student achievement. The study by Dori and Belcher [35], on the contrary, showed that external visualizations facilitate learning of electromagnetism. In addition, Kohnle, Baily, and Ruby [36] found that visualizations can facilitate the development of students' understanding of quantum mechanics, and Trindade and Fiolhais 
[37] showed that visualizations can be used for purposes of improving students' understanding about atomic orbitals.

Based on the above-mentioned facts, we conclude that physics teachers need to be very careful when choosing or designing external visualizations. Some general criteria on effectiveness of visualizations are provided by Reusser (as cited by Zou [25]), who asserts that pedagogically effective representations (a) help students to capture critical features of a problem, (b) direct students to make inferences, (c) bridge between concrete daily-life and abstract scientific concepts, and (d) reduce cognitive load.

In addition to the above-mentioned general criteria, it is particularly important to ensure that the external visualizations are in line with the content-specific characteristics of the internal representations we wish to develop [10]. Based on our analysis of key aspects of understanding wave optics, as well as on the analysis of general criteria for choosing or designing visualizations, we can set up several criteria on the characteristics of visualizations of light waves which are supposed to facilitate developing understanding of wave optics. Specifically, we should use representations of light waves which (a) make the superposition of light waves phenomenon less abstract to the students (e.g, using depictors that can easily be associated with waves at a fixed point of space), (b) make it easy to externally represent the information about phase differences when reasoning about superposition of light waves (i.e., the information about phase difference should be easy to infer from the visual appearance of depictors), (c) are handy when it comes to the procedure of adding waves (e.g., the possibility to be used even in contexts that require superposition of multiple light waves or the possibility to easily illustrate the interference phenomena at various points of the screen and not only at points of maximum constructive or destructive interference), and (d) facilitate continual referring to basic concepts [38].

In conventional high school teaching, most often the only approaches to visualization of light waves are the wave front representations, as well as occasional uses of sinusoidal curves, which are sometimes used to represent spatial wave trains and at other times they are used to represent the temporal change of the electric field vector at a fixed location. When sinusoidal curves are used for representing light waves, the information about the waves' amplitudes is inferred from the maximal height of the curves and information about phase difference is inferred from comparing the visual appearance of the corresponding curves. In conventional teaching, which includes superposition of multiple waves (e.g., single-slit and diffraction gratings), the use of these sinusoidal curves is typically avoided because "adding curves" becomes too cumbersome and impractical. One further argument against visualizing phase differences through the use of sinusoidal curves showing the temporal change of the electric field vector over time (at a fixed point of space) is related to the fact that students tend to misinterpret these curves by assigning them with spatial features. For example, they incorrectly assume that increasing the amplitude of light can result with light no longer fitting through the slit [2] or that the electromagnetic field is spatially confined by means of the sinusoidal curves representing the wave [17]. Finally, it has also been shown that some students believe that sinusoidal curves represent trajectories of photons [2].

Keating [39] took a somewhat different approach in utilizing sinusoidal curves in order to visualize multiple elementary waves that originate from the points inside the slit in single-slit diffraction (see Fig. 1).

One important positive aspect of Keating's [39] visualizations is the possibility of representing the continuous change of phases as we go from the wave that originates at the upper edge to the wave that originates at the lower edge of the slit in single-slit diffraction.

It seems that, in line with Keating's approach, light waves can be effectively represented by oscillating electric field vectors. Thereby, amplitudes of light waves are inferred from the maximal lengths of the oscillating electric field vectors and phase differences are inferred from comparing the appearance of oscillatory states of these vectors.

Compared to the sinusoidal representation of light waves, representing the light waves by oscillating electric field vectors is probably more practical because reasoning about superposition of waves boils down to adding vectors instead of adding curves. In this approach, students can be directed to make inferences about the oscillatory states of the electric field vectors (i.e., phases of the waves) at characteristic, subsequent instants of time. In other words, students are intensively engaged in predicting activities whereby they make continual reference to some basic wave optics concepts. This approach is probably intuitively appealing because it is similar to inferring information about amplitudes and oscillatory states from observing the oscillations of elastic springs. It seems that this feature is congruent with the bridging daily-life to abstract scientific concepts criterion mentioned by Reusser (as cited in Zou [25]).

Another approach to visualizing light waves is the use of phasor diagrams [40-42]. Worland and Moelter [40] pointed out that phasors can be effectively used in addition to standard algebraic analysis, both as a visual and as a quantitative tool for analyzing the superposition of an arbitrary number of light waves. According to Young and Freedman [43], by using phasors combining sinusoidal quantities with phase differences "becomes a matter of vector addition" (p. 1130), which helps us to describe and

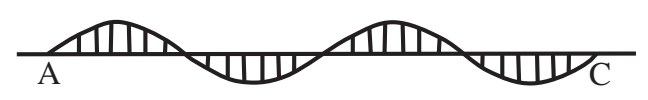

FIG. 1. Keating's [39] explanation of second minimum occurrence for single-slit diffraction; the length $A C$ represents the path difference of the two waves from the upper and lower edge. 
analyze quantities that vary sinusoidally with time. As a matter of fact, representing interference of light waves at a point of the screen boils down to drawing electric field vectors whose lengths correspond to the amplitudes of the waves arriving at that point of the screen, whereby phase differences are represented by angles between subsequent electric field vectors (i.e., phasors). The amplitude of the resultant wave is then simply found by vector addition. In other words, it is obvious that phasor diagrams convey (only) the most important information about light interference, i.e., information about the waves' amplitudes and phase differences. They may also be very handy for representing a wide spectrum of interference situationsit is easy to represent the superposition of multiple waves, and it is also relatively easy to represent the superposition of light waves characterized by arbitrary phase differences. Conventional teaching approaches at secondary school level typically resort only to discussions about maximum constructive or destructive interference. As a matter of fact, for arbitrary phase differences between interfering waves, it is relatively difficult to infer information about the resultant wave from the appearance of the given sinusoidal curves. This could explain the fact that students often do not understand that there is a continuum of brightness in interference patterns - they are only used to think about maximum constructive or destructive interference [18]. Alternatively, students can be shown phasor diagrams that represent interference phenomena at various points of the screen, and they can be asked to explain how these phenomena had occurred. In this way, we can lead the students through processes of "postdictions" [44], as well as through cycles of stating hypotheses and revisions of corresponding internal representations, which is at the heart of the abduction processes [32].

Although fulfilling most of the criteria on pedagogically effective visualizations of wave optics phenomena, it seems that phasor diagrams are often avoided in traditional wave optics instruction at high school (see Refs. [45-49]) and university level (see Refs. [50-52]).

\section{RESEARCH QUESTIONS AND HYPOTHESES}

Our research goal was to investigate whether the two alternative approaches to visualizing light waves could result in a higher level of understanding of wave optics compared to the conventional approach to teaching wave optics at the secondary school level. Specifically, we aimed to answer the following research question: What is the relative impact of three different approaches (conventional approach, temporal sequences of oscillating electric field vectors, phasors) to visualizing light waves on secondary school students' understanding of wave optics?

Based on the ideas that were presented in Sec. II, we formulated the following hypotheses:

(1) Visualizing light waves by oscillating electric field vectors will have a larger positive impact on students' understanding of wave optics, in comparison to the use of conventional visualizations of light waves, such as sinusoidal curves that visualize the change of the electric field vectors over time.

(2) Visualizing light waves by phasor diagrams will have a larger positive impact on students' understanding of wave optics, in comparison to the use of conventional visualizations of light waves, such as sinusoidal curves that visualize the change of the electric field vectors over time.

\section{RESEARCH DESIGN}

For the purpose of comparing the effectiveness of the three different approaches to visualizing light waves, a randomized post-test-only research design with three treatment groups was utilized. This is one of the most powerful designs in experimental research as the (careful) randomization ensures comparability of the groups before the treatment, and at the same time it effectively rules out a potential pretest-treatment interaction [53].

\section{PARTICIPANTS}

For our study the target population consists of 16-yearold secondary school students with no earlier formal learning experiences in wave optics and calculus, and only basic formal learning experiences in wave physics and trigonometry. The student sample for our study has been obtained by means of conventional sampling [54]. Concretely, in our study we included three classes of students $(N=85)$ who were enrolled in the second year of a four-year study program at one secondary school in Travnik, Bosnia and Herzegovina. The quoted study program is following a nine-year primary education, and upon its completion students can continue their education at higher education institutions. The program is aimed at students aged 15 to 18 , whereby our study mostly included 16 year olds.

In order to minimize the threats to internal validity, we randomly assigned the 85 students to three groups. Taking into account a potential influence of the gender variable, as well as the relatively small size of the gender subgroups, we decided to conduct the random assignment procedure separately for girls and boys, in order to ensure approximately equal proportions of boys and girls in the comparison groups. First, we randomly assigned girls to the three groups, and then the procedure was repeated for boys. In both cases the random allocation software by Saghaei [55] was used.

As a result of the described procedures, we obtained three groups of students that represented our comparison groups. However, due to factors such as illness and selection of few students (from each group) for a field trip, only 72 out of 85 students took the post-test. For that reason, all the statistics that are reported in our paper are 
TABLE I. Gender distribution and average physics and mathematics grades in the comparison groups $(N=72)$; grades are reported on a scale from 1 (fail) to 5 (excellent) and standard deviation is given in parentheses.

\begin{tabular}{lccc}
\hline \hline & $\begin{array}{c}\text { Conventional teaching } \\
(\mathrm{CT}) \text { group } \\
\left(n_{\mathrm{sc}}=24\right)\end{array}$ & $\begin{array}{c}\text { Sequences of electric } \\
\text { vectors }(\mathrm{SEV}) \\
\text { group }\left(n_{\mathrm{sv}}=25\right)\end{array}$ & $\begin{array}{c}\text { Phasors }(P) \text { group } \\
\left(n_{p}=23\right)\end{array}$ \\
\hline $\begin{array}{l}\text { Number of girls } \\
\begin{array}{l}\text { Number of boys } \\
\text { Average grade for physics } \\
\quad \text { as given in the half-year report) }\end{array}\end{array}$ & 14 & 15 & 13 \\
$\begin{array}{l}\text { Average grade for mathematics } \\
\text { (as given in the half-year report) }\end{array}$ & $3.71(0.75)$ & $3.8(0.96)$ & $3.69(0.88)$ \\
\hline \hline
\end{tabular}

based on the answers of these 72 students. The mere procedure of random allocation is typically considered to control for all possible extraneous variables and to make any pretreatment between-group differences only attributable to chance [53]. However, because in our study the groups were relatively small, we aimed to obtain some additional evidence that the random assignment had functioned reasonably well for our treatment groups. To that end, we analyzed the pretreatment between-group differences with respect to the gender variable, as well as with respect to physics and mathematics grades (see Table I).

Analyses of variance (ANOVA) showed that the pretreatment, between-group differences in average physics or mathematics grades were not statistically significant [for physics, $F(2,69)=0.11, \quad p=0.9$; for mathematics, $F(2,63)=0.39, p=0.68]$. Taking into account these results, as well as the fact that we randomly assigned students into groups, we claim that the comparison groups were reasonably equal to each other before the beginning of the treatment.

Before taking part in our study, students had not been taught about wave optics at all. As a matter of fact, they had only been taught about some basic wave physics concepts in primary school, as well as in the second year of secondary school. The primary school curricula in the Federation of Bosnia and Herzegovina foresee that ninth grade students learn about some basic concepts such as

TABLE II. Number of teaching hours devoted to research or teaching activities.

\begin{tabular}{ll}
\hline \hline Devoted time & \multicolumn{1}{c}{ Activity } \\
\hline $90 \mathrm{~min}$ & $\begin{array}{c}\text { Describing the wave nature of light; } \\
\text { superposition of coherent or incoherent } \\
\text { light waves; double slit interference } \\
\text { (development and application of concepts) } \\
90 \mathrm{~min}\end{array}$ \\
$\begin{array}{c}\text { Single slit diffraction. Diffraction gratings } \\
\text { (development and application of concepts) } \\
\text { Conceptual survey; survey of student attitudes } \\
\text { towards learning wave optics and } \\
\text { estimates of self-efficacy }\end{array}$ \\
\hline \hline
\end{tabular}

period, frequency, amplitude, or wavelength. Typically, primary school physics teachers devote five teaching hours to the following topics: waves, sources and types of waves; reflection and refraction of waves; sound. The concepts of wave interference and diffraction are not covered at the primary school level, at all. When it comes to the wave nature of light, the primary school students merely learn that light is an electromagnetic wave, as well as some facts related to the nature of the electromagnetic spectrum. Besides learning about waves in primary school, the students from our sample were taught about the same concepts again in the second year of secondary school. However, they had not studied about interference and diffraction before our experimental study at all. The participating school's curriculum foresees covering all general physics topics in the first two years of the secondary education (two class hours per week). Consequently, only a relatively low number of teaching hours can be devoted to teaching about wave optics. In our study, each group learned for four class hours about these topics (see Table II).

It should be also noted that students had not studied systematically about trigonometry in their mathematics classes before the start of our treatment. They were merely introduced to the definitions of basic trigonometric functions in some earlier physics classes (e.g., definitions of sine, cosine, and tangent of an angle in the context of the right triangle).

\section{TREATMENTS}

Our study was situated within the context of the regular curriculum. However, each group received teaching on wave optics phenomena and concepts based on a different approach. Concretely, three teaching approaches have been designed, each promoting different visualizations of light waves and their phase differences. In all three approaches, we intended to cover the same contents, i.e. to introduce basic wave optics concepts (e.g., wavelength, period, frequency, coherence, phase, path length) and to explain the most prominent phenomena, such as double-slit interference, single-slit diffraction, and optical grating patterns. 
When it comes to the general pedagogical format of the lessons, it should be noted that all three approaches build on interactive teaching environments through running simulations, conducting experiments, and holding discussions about the phenomena observed and visualizations utilized. Finally, it is important to say that the three teaching approaches were implemented as similar as possible to each other, with the exception of using different ways of visualizing the light waves.

In all situations, we used the model of linearly polarized light. If not explicitly stated otherwise, the light waves have been considered as monochromatic. Further, in the context of Young's experiment, the width of the slits has been considered to be infinitely small, so that we could approximate the slits as mutually coherent point sources of light. In all situations we considered the propagation of light through only one medium (i.e., air) and we discussed only situations in which light was perpendicularly incident on the slit mask.

Within the conventional teaching approach, light waves have been represented by visualizations of wave fronts, as well as by an occasional use of sinusoidal curves, in the way it is typically done in conventional teaching. As a matter of fact, in conventional approaches to teaching about light interference and diffraction, sinusoidal curves are most often used to visualize the mechanisms of minima or maxima occurrence within the context of double-slit interference [50], whereas in the contexts of single-slit diffraction and diffraction gratings often only path length differences between relevant rays are sketched [50]; i.e., no visualizations of light waves are used at all. We used a similar approach to visualizing light waves in the conventional teaching group. Throughout the treatment in the CT group, students were required to apply the formula that relates path difference and phase difference, in order to be in a position to reason about the result of superposition of the interfering waves (for typically covered situations, $\Delta s=0, \Delta s=\lambda / 2, \Delta s=\lambda)$. For some of the contents (e.g., double-slit interference) sinusoidal curves were used to help the students infer the results of the superposition of waves. Figure 2 illustrates how the occurrence of the first maxima and minima is accounted for by addition of sinusoidal curves at corresponding locations of the screen. The discussions of the characteristic situations of wave interference were followed with the requirement of generalizing the conclusions for purposes of deriving the conditions for the occurrence of interference minima or maxima.

Within the sequences of electric vectors approach, besides using the wave fronts representation, interfering light waves (at a fixed point of the screen) were visualized by drawing the corresponding electric field vectors, as well as their resultant in subsequent instants of time (e.g., $t=0 \mathrm{~s}, t=T / 4, t=T / 2$, etc). In this way, we wanted the students from the SEV group to develop internal

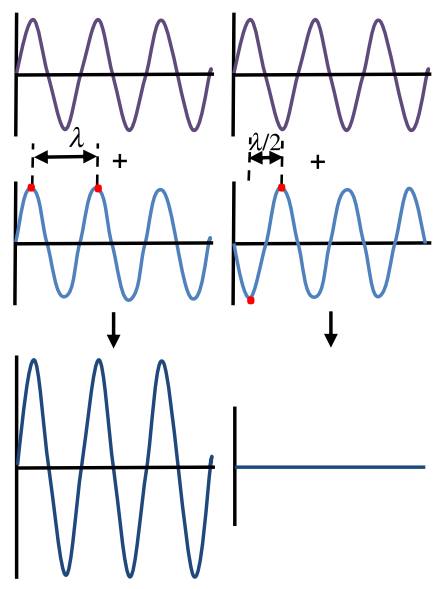

FIG. 2. CT approach: Visualizing the processes that underlie the occurrence of maxima and minima in double-slit interference.

representations which would allow them to get a (visual) idea about physical processes that occur at certain points of the screen where the interference pattern is formed. Figure 3 illustrates the occurrence of double-slit interference maxima by using a set of four static images showing the two interfering vectors and their resultant, at four subsequent instants of time.

Such a representation makes it easier to realize that even at points where maxima occur, the resultant electric field vector is sometimes zero and the irradiance is determined by the square of the amplitude of the resultant electric field vector. The auxiliary visualization was intended to help the students to think about the phase of the electric field vectors in different instants of time. However, establishing relationships between path length differences and phase differences of the interfering waves was the first thing students did in the SEV approach. Specifically, for a chosen point of the screen (typically characterized by $\Delta s=0, \Delta s=\lambda / 2$, $\Delta s=\lambda$ ) students first had to think about the phase

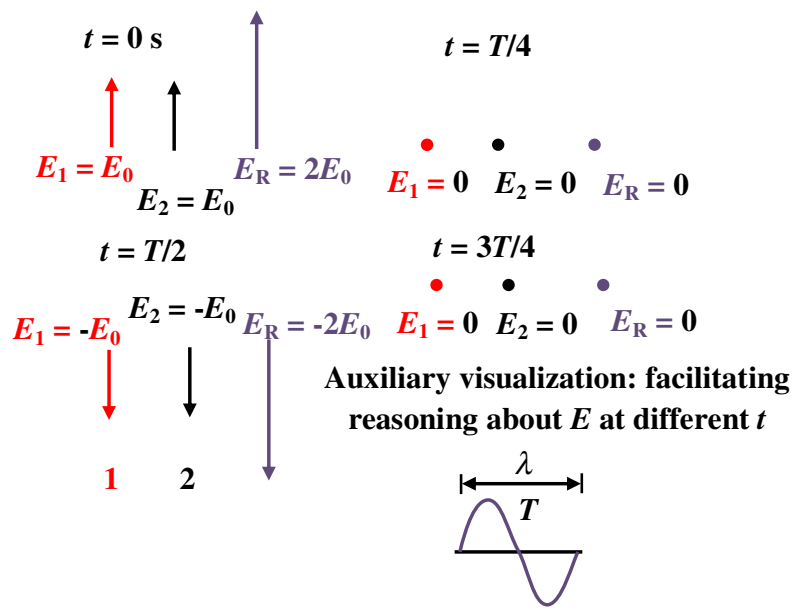

FIG. 3. SEV approach: Visualizing the processes that underlie the occurrence of maxima in double-slit interference. 
difference between interfering waves at that point of the screen. For that purpose they used the formula that relates path difference and phase difference. Thereafter, based on the obtained information about the phase difference, students were required to predict how the electric field vectors (which correspond to the interfering waves and their resultant) would visually be represented at subsequent instants of time (e.g., $t=0 \mathrm{~s}, t=T / 4, t=T / 2$, etc). Typically, we chose one of the electric field vectors to be at its positive amplitude state at the instant $t=0 \mathrm{~s}$, and the oscillatory state of other vectors has been inferred from the information about path difference. Again, the discussion about interference of waves at characteristic points of the screen was followed by derivation of the conditions for the occurrence of minima or maxima. As earlier noted, the idea of visualizing the phase distribution of multiple electric field vectors has also been used by Keating [39] in his attempt to explain the occurrence of minima in single-slit diffraction. We tried to apply this idea consistently in teaching other topics, too (e.g., double-slit interference and diffraction grating), as well as to further elaborate it by reasoning about the temporal change of the phase distribution. By including the factor of temporal change of electric field vectors at a given point of the screen, it became possible for us to think about the amplitude of the resultant electric field vector at that point of the screen.

Within the phasors $(P)$ approach, besides showing the wave front representation, we tended to visualize the interfering light waves by using phasors. Our didactical approach in this treatment group was mostly influenced by the way in which phasors are introduced in some textbooks for German gymnasia, such as Metzler Physik [56] and Dorn-Bader Physik [42]. Figure 4 illustrates how phasor diagrams can be used for explaining the interference pattern obtained in the double-slit experiment. Blue arrows represent the individual waves originating from the two slits and the red arrow represents the resultant wave. It can be nicely seen how continuous increasing of the phase difference (related to continuous increasing of path difference between corresponding waves) results in continuous decreasing of the amplitude of the resultant wave; i.e., it results in continuous decreasing of the irradiance of the screen. The phasor diagrams were primarily used as a didactical anchor for organizing discussions about physical processes which underlie the generation of the interference pattern at different points of the screen. In other words, the visual, qualitative potentials of phasor diagrams have been far more utilized than their quantitative potentials. The use of phasor diagrams facilitated the processes of abduction [32] - in multiple contexts students were asked to interpret how the given phasor diagrams could be used to account for the appearance of the obtained pattern at various points of the screen. We tried to overcome the students' difficulty of relating phasors to oscillating quantities [22]

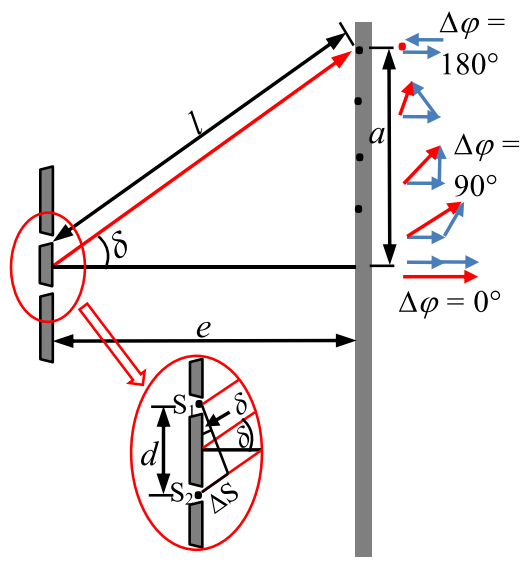

FIG. 4. $\quad P$ approach: Visualizing the processes that underlie the occurrence of the interference pattern in double-slit interference.

by introducing the phasor concept first within the context of a set of images that relate the rotation of a phasor to an oscillating elastic spring. Besides this attempt of "bridging," we also followed the introduction of the phasor concept with intensive application activities. Throughout the treatment, students often had to apply the formula that relates the path difference to phase difference, as well as to relate the length of the resulting phasor (amplitude of the resultant wave) to the irradiance at the corresponding location of the screen. Similarly, as in the other two groups, students were asked to generalize from concrete situations in which minima or maxima occur to general conditions for occurrence of interference minima or maxima.

Taking into account the fact that the sampled students had not studied in their mathematics classes about trigonometry and that they earlier had only been introduced to the definitions of basic trigonometric functions, the level of mathematization was relatively low in all three groups. The only occasion in which trigonometry has been applied was in deriving the formulas that relate the distance between adjacent slits or edges of the slit (in single-slit diffraction) and the diffraction angle with the path difference of corresponding waves. When it comes to the concept of irradiance, in each of the groups we merely pointed out that for interference of coherent light, in each point of the screen irradiance is proportional to the square of the amplitude of the resultant wave, i.e., electric field vector, at that point. Consequently, in all groups the teacher emphasized the importance of finding the amplitude of the resultant wave or electric field vector (at different points of the screen) and its relevance for the discussion of the appearance of the interference pattern. A more detailed overview of the implemented teaching activities is given in Supplemental Material [57].

Finally, it should also be noted that students in all classes were taught by the same teacher (age 25), who was their regular teacher. 


\section{INSTRUMENT}

The questionnaire for measuring understanding of wave optics has been specifically designed for this study. It is a simplified version of a comprehensive wave optics survey that we have been developing since 2012 and that has included multiple validation procedures (such as systematic domain and learning goal specification, expert ratings of items, think-aloud interviews and focused groups, written item try-out, etc).

\section{A. Structure of the instrument}

In order to answer our research question, we had to design a test that measures students' conceptual understanding of basic wave optics. We primarily based our operationalization of conceptual understanding on the earlier quoted definitions by Ford [26] and Micheal and Modell [27]. Specifically, the conceptual understanding of basic wave optics has been operationalized to include the students' ability to interpret various representations of wave motion, as well as the ability to apply the wave model of light in order to solve some qualitative problems. In many of the questions students were asked to predict what will happen with the interference pattern if certain characteristics of the experimental setup are modified.

Further, we had to specify the content domain to be covered by our test items. The specification of the content domain was based on the principle of alignment of instruction and assessment- the test was supposed to cover those contents that had been taught in classes: basic wave optics quantities (wavelength, phase, phase difference, amplitude, irradiance, frequency, period, coherence, path length difference), superposition, Young's double-slit experiment, single-slit experiment, and diffraction gratings. However, in order to be in the position to roughly estimate the treatment's influence on the ability of far transfer, we also included three items related to multiple-slit interference.

Our assessment instrument [Basic Wave Optics Survey $(B W O S)$ ] is given in the Supplemental Material [58] and its short description is provided in Table III.

Items 4 and 5 were adapted from the Light and Optics Conceptual Evaluation instrument [59] and items 9, 17, and 19 were inspired by the research of the Washington PER group [2,20,22].

One week after the treatment, the students were given 60 minutes to complete the described conceptual test and an attitude survey (which will be described in another paper). Students were told in advance that their achievement on the wave optics test will affect their physics grade in the endof-year report.

\section{B. Instrument quality}

In order to be in the position to estimate whether or not the students' test scores approximately represent interval measures of students' understanding of wave optics, we decided to evaluate our instrument from a Rasch modeling perspective [60]. Thereby, the measures of a person's ability can be considered to be approximately interval measures only if the test items fit the Rasch model [61]. For multiple-choice tests reasonable mean-square (MNSQ) infit and outfit statistics are between 0.7 and 1.3, whereby only values above 2 are said to be distorting or degrading

TABLE III. Short item descriptions.

\begin{tabular}{|c|c|c|c|c|}
\hline Item 1 & Item 2 & Item 3 & Item 4 & Item 5 \\
\hline $\begin{array}{l}\text { Phase difference } \\
\text { (spatial)-wave fronts }\end{array}$ & $\begin{array}{l}\text { Phase (temporal), } \\
\text { period }\end{array}$ & $\begin{array}{l}\text { Phase difference } \\
\text { (spatial)-sinusoidal } \\
\text { curve }\end{array}$ & $\begin{array}{l}\text { Superposition, } \\
\text { path difference, } \\
\text { phase difference }\end{array}$ & $\begin{array}{l}\text { Superposition, } \\
\text { path difference, } \\
\text { phase difference }\end{array}$ \\
\hline Item 6 & Item 7 & Item 8 & Item 9 & Item 10 \\
\hline $\begin{array}{l}\text { Double-slit interference, } \\
\text { order of the maximum } \\
\text { versus phase difference }\end{array}$ & $\begin{array}{l}\text { Double-slit interference, } \\
\text { different color of } \\
\text { light on different slits }\end{array}$ & $\begin{array}{l}\text { Double-slit interference, } \\
\text { influence of wavelength } \\
\text { on distance between } \\
\text { adjacent maxima }\end{array}$ & $\begin{array}{l}\text { Single-slit } \\
\quad \text { diffraction } \\
\quad(\text { width }<\lambda)\end{array}$ & $\begin{array}{l}\text { Single-slit diffraction, } \\
\text { influence of slit } \\
\text { width on the } \\
\text { width of the maxima }\end{array}$ \\
\hline Item 11 & Item 12 & Item 13 & Item 14 & Item 15 \\
\hline $\begin{array}{l}\text { Single-slit diffraction, } \\
\text { influence of path } \\
\text { difference }\end{array}$ & $\begin{array}{l}\text { Single-sit diffraction, } \\
\text { temporal change of the } \\
\text { resultant electric } \\
\text { field vector at central } \\
\text { maximum }\end{array}$ & $\begin{array}{l}\text { Single-slit diffraction, } \\
\text { temporal change } \\
\text { of the resultant } \\
\text { vector at minima }\end{array}$ & $\begin{array}{l}\text { Single-slit diffraction, } \\
\text { influence of slit width }\end{array}$ & $\begin{array}{l}\text { Diffraction grating, } \\
\text { influence of } \\
\text { wavelength on } \\
\text { distance between } \\
\text { adjacent maxima }\end{array}$ \\
\hline Item 16 & Item 17 -far transfer & Item 18-far transfer & Item 19-far transfer & \\
\hline $\begin{array}{l}\text { Diffraction grating, } \\
\text { influence of the } \\
\text { grating constant }\end{array}$ & $\begin{array}{l}\text { Multiple-slit interference, } \\
\text { influence of increasing } \\
\text { the number of slits }\end{array}$ & $\begin{array}{l}\text { Four slit interference, } \\
\text { path difference, } \\
\text { condition for minima }\end{array}$ & $\begin{array}{l}\text { Comparing the patterns } \\
\text { of double-slit and } \\
\text { three-slit interference }\end{array}$ & \\
\hline
\end{tabular}


TABLE IV. The distribution of MNSQ infit and outfit statistics for our test items; the provided interpretation guidelines are recommended by Wright and Linacre [62].

\begin{tabular}{lcccc}
\hline \hline & $\begin{array}{c}<.5 \text { (overfit, less } \\
\text { productive, } \\
\text { but not degrading) }\end{array}$ & $\begin{array}{c}0.5-1.5 \text { (productive } \\
\text { for measurement) }\end{array}$ & $\begin{array}{c}1.5-2.0 \\
\text { (unproductive, } \\
\text { but not degrading) }\end{array}$ & $\begin{array}{c}>2 \text { (distorting or } \\
\text { degrading } \\
\text { the measurement) }\end{array}$ \\
\hline MNSQ infit & 0 & 14 items & 1 item & 0 \\
MNSQ outfit & 3 items & 9 items & 2 items & 1 item \\
\hline \hline
\end{tabular}

the measurement system [62]. The main difference between the infit and outfit statistics is related to the fact that the MNSQ infit statistics focuses more on response strings close to the item difficulty and it is a measure that is less sensitive to outliers (careless mistakes and lucky guesses) than the MNSQ outfit [63].

The results of the Rasch analysis of our students' answers on all 19 test items showed that items 7, 8, 10, and 15 were underfitting the Rasch model. In order to improve the Rasch compliance of our item set, the mentioned items were discarded from further Rasch analyses. After rerunning the Rasch analysis on the remaining 15 items, the goodness of fit improved. The distribution of MNSQ infit and outfit statistics for the data obtained from our 15-items set is given in Table IV.

Taking into account the fact that merely one item (item 19) is identified to be degrading the system (but only based on the MNSQ outfit), we could say that the level of fit between our data and the Rasch model is relatively satisfying. All the analyses below are based on the data related to the 15 -items set, which proved to be reasonably Rasch compliant. For a Rasch-compliant set of items, it makes perfect sense to calculate participants' test scores by summing their scores over individual items [61]; i.e., it is reasonable to treat the raw scores as approximately interval measures. Besides that, raw scores are characterized by an intuitive attractiveness; i.e., they are easier to interpret compared to Rasch measures of ability. Consequently, we decided to approach answering of our research questions by performing statistical analyses on students' raw scores (see Sec. VIII).

Finally, we also explored the reliability and content validity of our Rasch-compliant item set (15 items).

When it comes to the reliability of the test scores, it should be noted that Cronbach's alpha of the test amounted to 0.85 . Thus, the reliability of our test can be considered to be relatively high (see Ref. [64]). In addition, the average discrimination coefficient, as measured by the corrected item-total correlation, amounted to 0.48 . Item discrimination indices above 0.3 can be considered as satisfying [65]. For only two items the discrimination index was below this value (item 12, $r=0.26$; item 17, $r=0.12$ ). Although being relatively unproductive, these two items were kept in the item set for purposes of ensuring a higher level of content validity.
Finally, it should be noted that the item difficulty index varied between 0.21 and 0.79 , with a mean of 0.56 . An average item difficulty index of 0.5 is considered to be optimal [66].

When it comes to content validity, a rough estimate can also be obtained by comparison of our test items (see Supplemental Material [58]) with the contents covered in class (see Supplemental Material [57]). From Table III (and from the test instrument) it can be seen that our items covered the concepts of wavelength, phase, phase difference, period, constructive or destructive interference, coherence or incoherence, double-slit interference, single-slit diffraction, diffraction grating, and multiple-slit interference (far transfer items). These are the most prominent topics covered in typical introductory courses of physics when it comes to wave optics.

Additionally, the fact that the average item difficulty index was very close to the value that is considered to be optimal in relevant literature provides one more evidence for the suitability of our item set, i.e., for a good level of assessment-instruction alignment.

\section{RESULTS}

We open this section with a descriptive statistics analysis aimed at providing an intuitive picture about the betweentreatment differences in the understanding of basic wave optics. Thereafter, the research hypotheses will be checked by means of inferential statistics. Finally, subscale analyses will be performed for purposes of obtaining further insight into the structure of between-group differences.

\section{A. Between-group differences-Descriptive statistics}

A first insight into the between-group differences on the conceptual test can be obtained through analyses of the box plots presented in Fig. 5.

We can see that the highest medians are associated with the phasors treatment, and the lowest medians with the conventional treatment.

We can gain further insight into between-treatment differences by comparing average test scores and percentages of correct answers across the groups (see Table V).

The largest variations of scores are observed in the CT group, and the smallest in the $P$ group. 


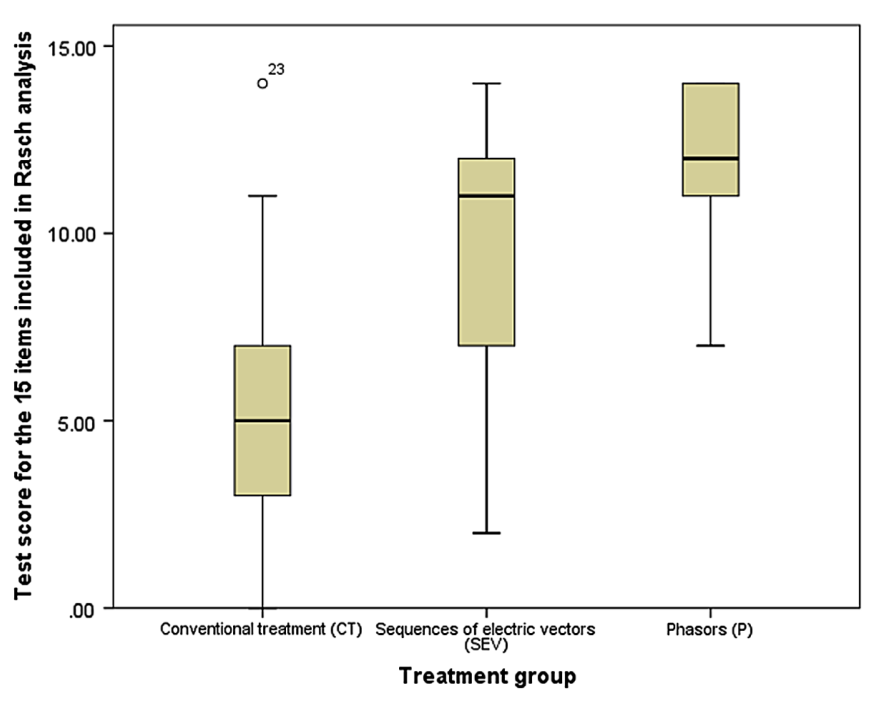

FIG. 5. Box plots that describe the distribution of test scores across comparison groups. Theoretically, the test-score scale ranges from 0 to 15 points. Circles represent outliers.

\section{B. Between-group differences-Inferential statistics}

In order to assess the suitability of running an ANOVA analysis on our data, we checked the homogeneity of variance assumption, as well as the normality assumption for our data. Thereby, Levene's statistic proved to be nonsignificant, which suggests that the homogeneity of variances assumption has been fulfilled. In addition, the normality assumption was checked through visual inspection of $Q-Q$ plots [67] for test scores in each individual group, as well as by calculations of the Saphiro-Wilk statistics. Thereby, it has been found that the normality assumption was not fulfilled for the test scores of students from the phasors group.

Therefore, we decided to conduct the Kruskal-Wallis test on our data, whereby we used the students' test scores as the dependent variable. The Kruskal-Wallis test showed that students' understanding of light interference and diffraction was significantly affected by the type of teaching treatment they received: $H(2)=30.4, p<0.001$.

Pairwise comparisons with adjusted $p$ values showed that students from the conventional teaching group were significantly outperformed by students from the phasors group (adjusted $p<0.001, r=0.79$ ), as well as by the

TABLE V. Average test scores and proportions of correct answers across groups; standard deviations are given in parentheses. Theoretically, the test-score scale ranges from 0 to 15 points.

\begin{tabular}{lccr}
\hline \hline & $\mathrm{CT}(n=24)$ & $\mathrm{SEV}(n=25)$ & $P(n=23)$ \\
\hline Average test score & $5.46(3.37)$ & $9.72(3.34)$ & $11.78(2.24)$ \\
Proportions of & $0.36(0.48)$ & $0.65(0.48)$ & $0.78(0.41)$ \\
$\quad$ correct answers & & & \\
\hline \hline
\end{tabular}

students from the group that learned wave optics by using series of static images showing oscillating electric field vectors (adjusted $p=0.001, r=0.5$ ).

\section{Between-group differences on subscales and discarded items}

Insight into between-group differences on individual subscales can be gained by inspection of Table VI.

It is also interesting to provide information about the relationship between understanding of basic wave optics concepts (primarily concept of phase) and the understanding of prominent wave optics phenomena, as described by the subscales 2 (two source interference), 3 (single-slit diffraction), and 4 (far-transfer items, mainly related to multiple slit interference). These relationships can be analyzed based on corresponding correlation coefficients (see Table VII).

When it comes to between-group differences on individual items, a detailed overview of results is provided in Supplemental Material [68]. Here, we focus our attention only on presenting the between-group differences on items that had to be discarded within the Rasch modeling process; i.e., we will describe the results for items $7,8,10$, and 15 . To that end, it should be noted that only on item 7 the conventional group largely outperformed one of the experimental groups (i.e., the SEV group), whereby the difference in the percentage of correct answers amounted to $33.5 \%$ (i.e., $37.5 \%-4 \%$ ). This item required the students to answer what will happen to the red laser light (double-slit interference) pattern if one of the slits is again illuminated with red laser light and the other slit with green laser light. When speaking about the other discarded items, it should be noted that on item 15 the students' achievement in all three groups was surprisingly low-the percentage of correct answers was $12.5 \%, 8 \%$, and $8.7 \%$ in the CT, $\mathrm{SEV}$, and $P$ group, respectively. This item merely required the students to predict how the distances between diffraction maxima change if the diffraction grating is illuminated with green laser light instead with red laser light. It is interesting to note that the discarded item 8 was also related to predicting the change in the double-slit interference pattern due to the change of the wavelength of laser light, and on this item the $P$ group outperformed the other two groups. For item 10, which required the students to relate the width of the single slit to the width of the diffraction maxima, the percentage of correct answers was much higher in each of the experimental groups than in the conventional teaching group.

\section{DISCUSSION}

Our results showed that each of the experimental groups significantly outperformed the conventional teaching group. The corresponding differences in the post-treatment understanding of basic wave optics may be considered as 
TABLE VI. Between-group comparisons across subscales. Note that only the items from the Rasch-compliant set were included. Difficulty index (DI), mean score $(M)$, and standard deviation (SD) are provided.

\begin{tabular}{|c|c|c|c|}
\hline $\begin{array}{l}\text { Subscale } 1(\alpha=0.79) \text { : } \\
\text { Basic wave concepts } \\
(\text { items } 1,2,3)\end{array}$ & $\begin{array}{l}\text { Subscale } 2(\alpha=0.69) \text { : } \\
\text { Two-source interference } \\
\quad \text { (items } 4,5,6)\end{array}$ & $\begin{array}{l}\text { Subscale } 3(\alpha=0.58) \text { : } \\
\text { Single-slit diffraction } \\
\quad \text { (items } 9,11-14)\end{array}$ & $\begin{array}{c}\text { Subscale } 4(\alpha=0.41) \text { : } \\
\text { Far transfer } \\
\text { (items } 17,18,19)\end{array}$ \\
\hline $\begin{array}{l}\mathrm{CT}: \mathrm{DI}=0.37, M=1.12, \\
\quad \mathrm{SD}=1.03\end{array}$ & $\begin{array}{l}\mathrm{CT}: \mathrm{DI}=0.39, M=1.17 \\
\quad \mathrm{SD}=1.01\end{array}$ & $\begin{array}{l}\text { CT: DI }=0.39, M=1.96 \\
\quad \mathrm{SD}=1.23\end{array}$ & $\begin{array}{l}\mathrm{CT}: \mathrm{DI}=0.21, M=0.62 \\
\quad \mathrm{SD}=0.77\end{array}$ \\
\hline $\begin{array}{l}\text { SEV: DI }=0.8, M=2.4 \\
\quad \mathrm{SD}=1.08\end{array}$ & $\begin{array}{l}\text { SEV: } \mathrm{DI}=0.83, M=2.48 \\
\quad \mathrm{SD}=0.82\end{array}$ & $\begin{array}{l}\text { SEV: } \mathrm{DI}=0.62, M=3.12 \\
\quad \mathrm{SD}=1.56\end{array}$ & $\begin{array}{l}\text { SEV: DI }=0.23, M=0.68 \\
\quad \mathrm{SD}=0.9\end{array}$ \\
\hline $\begin{aligned} P: \mathrm{DI} & =0.94, M=2.83 \\
\mathrm{SD} & =0.49\end{aligned}$ & $\begin{aligned} P: \mathrm{DI} & =0.93, M=2.78 \\
\mathrm{SD} & =0.52\end{aligned}$ & $\begin{aligned} P: \mathrm{DI} & =0.7, M=3.52 \\
\mathrm{SD} & =1.2\end{aligned}$ & $\begin{aligned} P: \mathrm{DI} & =0.57, M=1.7 \\
\mathrm{SD} & =0.7\end{aligned}$ \\
\hline
\end{tabular}

TABLE VII. Correlation between understanding basic wave concepts and understanding of prominent light interference and diffraction phenomena.

\begin{tabular}{cccc}
\hline \hline & $\begin{array}{c}\text { Two-source } \\
\text { interference }\end{array}$ & $\begin{array}{c}\text { Single-slit } \\
\text { diffraction }\end{array}$ & $\begin{array}{c}\text { Far-transfer } \\
\text { items }\end{array}$ \\
\hline Basic wave & $r=0.8$, & $r=0.52$, & $r=0.36$, \\
concepts & $p<0.001$ & $p<0.001$ & $p=0.002$ \\
\hline \hline
\end{tabular}

large. Thereby, the effectiveness of the teaching approach which utilized phasors proved to be especially prominent. In our opinion, it is highly unlikely that the large and statistically significant between-group differences on the post-test are a result of significant and large pretreatment differences, i.e., a result of a malfunctioning random allocation. As a matter of fact, even if the sample size is small to modest (and there are small-to-modest correlations between outcomes and confounding variables), it is unlikely that a type I error will occur as a result of random allocation failing to produce equivalence for a potential confound [69].

Taking into account that this is the first experimental study on the effectiveness of phasors and series of static diagrams in teaching about wave optics, we cannot directly compare our findings with earlier research. However, when it comes to the series of diagrams showing dynamic physical processes in characteristic, subsequent instants of time, it should be noted that their effectiveness has already been shown within the context of teaching onedimensional kinematics [70].

The between-treatment differences most likely resulted from the fact that the experimental treatments were more successful in developing students' internal representations of light waves and interference phenomena. Specifically, throughout the experimental treatments (SEV and $P$ ) students were required to consistently use the same entities (phasors or oscillating electric field vectors) for purposes of accounting for the nature of interference pattern in different points of the screen. In Halloun's [44] terms, we could say that the experimental treatments provided the students with practical depictors on which they can mentally perform actions, i.e., qualitative reasoning. As a matter of fact, according to Greca and Moreira [8], students' use of drawings can be an indicator of qualitative reasoning, whereas avoiding of drawings and mere usage of propositional representations (e.g., definitions and formulas) when communicating physics ideas can be an indicator that students do not comprehend the phenomena at hand. In our study, we used drawings (curves, sequences of electric field vectors, and phasors) to communicate our qualitative understanding of wave optics to students. By consistently using these external representations and asking the students to reason about them, we attempted to help them to internalize these representations. In that sense, it should be noted that in the SEV group there were more students who created drawings on the test sheets than in the other two groups. It is also interesting to note that students from all three groups scored very low on item 15 , which merely required them to infer the consequences of changing the wavelength of light on the visual appearance of the diffraction pattern produced by an optical grating. This item, as well as several other items for which low scorings have been detected, would be very easy to solve if one would approach them by reasoning based on propositional representations (e.g., equations that represent conditions for occurrence of minima or maxima). One of the reasons for low students' results on these items could be related to the fact that they consistently attempted to use visual thinking for solving items, which proved to be a highly demanding task in certain contexts (e.g., in contexts of increasing the wavelength of light and modifying the width of the slits).

Typically, in conventional teaching the visualizations of interfering light waves are not used consistently (e.g., sinusoidal curves are used only in teaching about doubleslit interference), which often hinders the development of internal representations of light interference. One of the reasons for sinusoidal curves not being consistently used to account for the appearance of the interference pattern is probably related to the fact that representing interference of waves means summing of curves, which becomes rather cumbersome and impractical when there are multiple interfering waves. Further, in the study by Ambrose et al. [17], it 
has been shown that some students misinterpret the sinusoidal representations of waves. Sengoren [18] argues for representing light propagation from the source by spherical wave surfaces and corresponding arrowed lines rather than by sinusoidal curves. These ideas seem to be in line with Maurines [4], as well as with the experimental approaches to teaching used in this study (see Supplemental Material [57]).

Besides the effect of visualizing the relevant depictors and noncomplicated manipulations with vectors compared to manipulations with curves, the relative advantage of the experimental treatments over the conventional treatment could also be related to the fact that the use of phasors and sequences of electric field vectors provided more useful anchoring contexts for the development of classroom discussions. In these discussions students mostly had to account for the appearance of the screen at certain points, while using and iteratively improving their visual mental models (influenced by external visualizations) of light interference and diffraction. We believe that such an approach provides a fruitful context for the abduction processes [32], which are supposed to be at the heart of mental model development in physics.

When it comes to students' achievement on the individual subscales, it can be noted that the understanding of light interference or diffraction phenomena is significantly related to students' understanding of basic wave optics concepts, whereby the effect sizes for less complex phenomena prove to be large, and for more complex phenomena, the effect size is moderate. In addition, as the complexity of the content domain increases, the item difficulty also increases, which is in line with our expectations. Thereby, only in the phasors group the average performance stays relatively high, across all subscales. The main limitation of the SEV approach is related to the fact that it did not prove to be successful in developing students' ability for far transfer. However, it is very important to note that in both experimental groups the understanding of basic wave optics concepts and phenomena (subscale 1 and 2) was at a mastery level; i.e., the performance of students from experimental groups on the mentioned subscales was above $80 \%$.

The superiority of the experimental groups on the first two subscales (basic concepts and phenomena) could be explained by the fact that the visualizations provided in the experimental groups were more successful with respect to the feature of "directing the students to make inferences" (Ref. [25], p. 25). Consequently, the students from experimental groups applied the basic concepts consistently (because experimental visualizations could be used in multiple contexts) and more frequently. Throughout, the SEV treatment students were required to predict oscillatory states of electric field vectors (i.e., phases of the waves) at characteristic, subsequent instants of time. Similarly, the $P$ treatment allowed us to engage the students in "postdicting" [44] activities, which required the application of basic concepts such as path length difference and phase difference. This probably resulted in a better learning of these concepts in the experimental groups. As a matter of fact, Bybee, Powell, and Trowbridge [38] consider "continual reference to concepts" (p. 149) to be one of the key activities in science teaching.

The relative superiority of the phasors approach when it comes to far-transfer items, i.e., items that assess the understanding of multiple-slit interference, is in line with the fact that phasors are typically introduced for purposes of teaching multiple-slit interference in introductory courses of physics at the university level. We have shown that a qualitative version of the phasors approach can also be relatively effective for teaching about multiple-slit interference even at the upper-secondary school level, as is already done in German gymnasia. The relative superiority of phasor diagrams within the context of multipleslit interference could be related to the fact that it is relatively simple to arrange the phasors in order to demonstrate conditions for minima. Minima occur each time that the tip of the last phasor touches the tail of the first phasor-for example, in four waves interference the angle between each of the subsequent phasors must be $90^{\circ}$ in order to obtain the first minimum. On the other hand, it is more difficult to visualize the first arrangement of four electric field vectors which add to give a zero vector, at each instant of time (SEV approach). It is even more difficult to find the first arrangement of four sinusoidal curves that results with a horizontal line, i.e., with maximum destructive interference $(\mathrm{CT})$.

Finally, it should be noted that for the randomized, posttest-only control group design there are only three potential threats to internal validity [53]: experimenter effect, subjects effect, and diffusion of treatment.

First, we will discuss the potential experimenter threat. The teacher, who is at the same time the second author of this manuscript, was aware of the research question and hypotheses. She was asked to deliver the lectures in line with lesson plans that had been primarily prepared by the first author of this article. These lesson plans were prepared in detail for purposes of ensuring the interventions to be implemented as planned. An outline of the lesson plans has been provided in Supplemental Material [57] so that every reader can develop their own assessment of how the teaching approaches compare. The lesson plans were thoroughly discussed between the teacher and first author of the paper in order to ensure a common understanding of the key ideas before the start of the experimental study. The teacher's philosophy of teaching could be described as predominantly constructivistic, which means that her teaching paradigm was generally consistent with the specified lesson designs. Being inexperienced with the phasors approach, she perceived her preparations for the phasors approach as most challenging, and the SEV approach as most intuitively appealing. Based on the teacher's self-reflection that followed after the instruction, 
we concluded that there were no issues in implementing the detailed lesson plan specifications for any of the groups. Finally, it should be noted that the teacher can be characterized as a talented but relatively inexperienced physics teacher (it was her first year of teaching). Nevertheless, during her own secondary and tertiary education the teacher had much more experience with the traditional wave optics representations, which means that an experimenter threat to internal validity is unlikely because before this teaching experiment the teacher was more familiar with the CT approach.

When it comes to a potential subjects effect, it should be noted that students from each group knew in advance that they participated in a teaching experiment and they knew in advance that their post-test results would influence their physics grade. Consequently, the subjects effect [53] does not seem to be a reasonable alternative explanation for the observed between-group differences.

It is reasonable to assume that the students also have learned about wave optics outside the teaching environment, which means that the effective learning time was larger than only four class hours.

Thereby, one potential threat to the internal validity of our research design was the diffusion of treatments.

In order to gain information about that threat, we asked the students to specify materials from which they had learned about wave optics (see Supplemental Material [58]). It has been shown that a large majority of students learned exclusively from the notes they took in class (e.g., only two students from the $P$ group stated that they used the textbook in addition to the lecture notes). Consequently, the diffusion of treatments threat seems to be rather unlikely in the context of our study.

Taking into account that we used conventional sampling, one has to be cautious when it comes to the generalization of the results of this study. According to Johnson and Christensen [54], the results of studies which use conventional sampling can be generalized to some hypothetical population that is similar to the sample.

For our study, the hypothetical population consists of 16year-old secondary school students with no earlier formal learning experiences in wave optics and calculus, and only basic formal learning experiences in wave physics and trigonometry.

If we take the grade point average (GPA) at the end of primary school (ninth grade) as a criterion measure, students from our hypothetical population can be considered to be of average ability compared to the overall population of students (of same age) who are enrolled in four-year secondary school programs (10th to 13th grade) in Bosnia and Herzegovina.

\section{SUMMARY AND CONCLUSION}

Making high-quality decisions on the choice of visualizations is particularly important in the context of conceptual level courses in which, due to curricular restrictions, resorting to sophisticated mathematical apparatus is avoided. This is often the case with teaching wave optics to secondary school students. In our study, we aimed to evaluate the influence of different approaches to visualization of light waves on students' understanding of basic wave optics. For that purpose, we randomly assigned secondary school students (mostly 16-year olds) into three comparison groups. In the CT group a conventional treatment characterized by the occasional use of sinusoidal curves has been implemented, whereas in the experimental groups we visualized light waves by temporal sequences of oscillating electric field vectors (SEV) and phasor diagrams, respectively. The treatments lasted for four class hours, after which the students were administered the Basic Wave Optics Survey.

The most important general conclusions that can be drawn from the results of our study are as follows:

- This study adds further evidence on the importance of careful choice or design of visualizations for teaching physics. The effectiveness of visualizations depends on the level to which the mental activity facilitated by the visualizations engenders the construction of mental representations [10]. Consequently, the design of visualizations should be based on a deep understanding of internal representations we wish to develop for a specific content domain of physics.

- This study also appears to confirm the idea that conceptual-level physics courses can teach important physics concepts in a meaningful way.

- The development of internal representations is facilitated through a consistent use of external representations, followed by application activities (particularly, predicting and "postdicting" activities) within the context of these representations. It is also desirable to use the external visualizations for purposes of engaging the students in cycles of hypothesizing and revision of internal representations, i.e., to engage them in abduction processes [32].

Our analysis of students' answers also gave rise to the following specific conclusions, relevant for learning and teaching wave optics:

- The visualizations of interfering light waves by phasors or series of diagrams showing the interfering electric field vectors at subsequent instants of time substantially help the students to develop an understanding about mechanisms that underlie the formation of interference patterns. The same cannot be said for the inconsistent use of sinusoidal curves typically displayed in conventional treatments.

- The visualizations used within experimental treatments seem to provide fruitful anchoring contexts for classroom discussions directed at the application and reinforcement of basic wave optics concepts.

- The phasors approach proved to be most effective, and this study showed that a qualitative variant 
of the phasors approach can be successfully used even when working with upper secondary school students.

The limitations of our treatments and study design are as follows:

- The conclusions from our study are limited to teaching wave optics to upper secondary school students with no earlier formal learning experiences in wave optics and calculus, and only basic formal learning experiences in wave physics and trigonometry.

- The conclusions of our study are based on results obtained from a relatively small sample of students.

- The duration of teaching treatments was relatively short, and the temporal stability of the established knowledge schemas has not been probed by means of retention studies. A longer learning time would certainly help students developing an (even) deeper knowledge and thus a better understanding of wave optics.

- Even after our experimental treatments, not all aspects of the model of wave interference were developed at a satisfactorily level-e.g., our approach failed to facilitate students' thinking about the effects of changing wavelength on the appearance of interference pattern, and the concept of light coherence did not develop sufficiently either.
- The wave fronts representation has been used in all groups in the same manner, but it has not been maximally utilized for organizing many application activities within the context of this representation.

- If students are presented with diagrams showing the electromagnetic character of light waves, concerted efforts are required to help the students understand these diagrams [17].

Our further research will be primarily directed at finding ways to remove the identified weaknesses of our experimental teaching approaches related to developing a better understanding of the concept of coherence, as well as to the application of external visualizations for purposes of inferring the consequences of the change of wavelength on the appearance of the interference pattern. More application activities will also be provided for facilitating the development of students' understanding regarding the mere concept of propagation of light waves. Generally, we will attempt to design a teaching approach that makes use of as many as possible carefully combined, complementary representations of propagation of light waves, the processes of their superposition, as well as of the results of the superposition processes. Consequently, our next study will be implemented within the context of a curriculum that allows for more mathematization, as well as for devoting more class hours to the teaching about wave optics.
[1] G. L. Rogers, Teaching physical optics, Phys. Educ. 3, 69 (1968).

[2] B. S. Ambrose, P. S. Shaffer, R. N. Steinberg, and L. C. McDermott, An investigation of student understanding of single-slit diffraction and double-slit interference, Am. J. Phys. 67, 146 (1999).

[3] P. Colin and L. Viennot, Using two models in optics: Students' difficulties and suggestions for teaching, Am. J. Phys. 69, S36 (2001).

[4] L. Maurines, Geometrical reasoning in wave situations: The case of light diffraction and coherent illumination optical imaging, Int. J. Sci. Educ. 32, 1895 (2010).

[5] A. Coetzee and S. N. Imenda, Alternative conceptions held by first year physics students at a South African university of technology concerning interference and diffraction of waves, Res. High. Educ. J. 16, 1 (2012).

[6] E. M. Colombo, M. Jaen, and L. C. de Cudmani, The concept of coherence of learning physical optics, SPIE Proceedings Vol. 2525, edited by M. J. Soileau (SPIEInternational Society for Optics and Photonics, Bellingham, WA, 1995), pp. 452-458.

[7] R. D. Knight, Five Easy Lessons: Strategies for Successful Physics Teaching (Addison-Wesley, San Francisco, CA, 2004).
[8] I. M. Greca and M. A. Moreira, The kinds of mental representations-models, propositions and images-used by college physics students regarding the concept of field, Int. J. Sci. Educ. 19, 711 (1997).

[9] N. Nersessian, Creating Scientific Concepts (MIT Press, Cambridge, MA, 2008).

[10] D. N. Rapp and C. N. Curby, in Visualization: Theory and Practice in Science Education, edited by M. Reiner, J. K. Gilbert, and M. Nakhleh (Springer, Dordrecht, 2008), pp. 29-53.

[11] National Research Council, A Framework for K-12 Science Education (National Academies Press, Washington, DC, 2012).

[12] D. J. Grayson and D. Donelly, Using education research to develop waves courseware, Comput. Phys. 10, 30 (1996).

[13] S. Vokos, P. S. Shaffer, B. S. Ambrose, and L. C. McDermott, Student understanding of the wave nature of matter: Diffraction and interference of particles, Am. J. Phys. 68, S42 (2000).

[14] J. H. Wandersee, J. J. Mintzes, and J. D. Novak, Handbook of Research on Science Teaching and Learning (MacMillan, New York, 1994), pp. 177-210.

[15] P. Hubber, Year 12 students' mental models of the nature of light, Res. Sci. Educ. 36, 419 (2006). 
[16] M. Watts, Student conceptions of light: A case study, Phys. Educ. 20, 183 (1985).

[17] B. S. Ambrose, P. R. L. Heron, S. Vokos, and L. C. McDermott, Student understanding of light as an electromagnetic wave: Relating the formalism to physical phenomena, Am. J. Phys. 67, 891 (1999).

[18] S. K. Sengoren, How do Turkish high school graduates use the wave theory of light to explain optics phenomena?, Phys. Educ. 45, 253 (2010).

[19] A. Zietsman and J. Clement, The role of extreme case reasoning in instruction for conceptual change, J. Learn. Sci. 6, 61 (1997).

[20] K. Wosilait, Ph.D. thesis, University of Washington, 1996.

[21] M. McCloskey, Intuitive physics, Sci. Am. 248, 122 (1983).

[22] K. Wosilait, P. R. Heron, P.S. Shaffer, and L. C. McDermott, Addressing student difficulties in applying a wave model to the interference and diffraction of light, Am. J. Phys. 67, S5 (1999).

[23] A. Stefanel, M. Michelini, and L. Santi, in Proceedings of the 14th Annual International Symposium "Frontiers of Fundamental Physics," Marseille, 2014 (SISSA, Trieste, 2014).

[24] B.-S. Eylon and U. Ganiel, Macro-micro relationships: The missing link between electrostatics and electrodynamics in students' reasoning, Int. J. Sci. Educ. 12, 79 (1990).

[25] B.S.X. Zou, Ph.D. thesis, The Ohio State University, 2000.

[26] K. Ford, Ph.D. thesis, Southern University and A and M College, Baton Rouge, 2011.

[27] J. Michael and H. I. Modell, Active Learning in Secondary and College Science Classrooms: A Working Model for Helping the Learner to Learn (Routledge, London, 2003).

[28] D. E. Meltzer, Relation between students' problem-solving performance and representational format, Am. J. Phys. 73, 463 (2005).

[29] B. Ibrahim and N. S. Rebello, Representational task formats and problem solving strategies in kinematics and work, Phys. Rev. ST Phys. Educ. Res. 8, 010126 (2012).

[30] M. Eysenck and M. Kean, Cognitive Psychology: A Student's Handbook (Erlbaum, London, 1990).

[31] M. Hegarty, in Proceedings of the Twenty-Fourth Annual Conference of the Cognitive Science Society (Lawrence Erlbaum Associates, Mahwah, NJ, 2002), Vol. 22, p. 40.

[32] J. J. Clement and M. S. Steinberg, Step-wise evolution of mental models of electric circuits: A "learning-aloud" case study, J. Learn. Sci. 11, 389 (2002).

[33] S. Ainsworth, in Visualization: Theory and Practice in Science Education, edited by M. Reiner, J. K. Gilbert, and M. Nakhleh (Springer, Dordrecht, 2008), pp. 191-208.

[34] D. Geelan, M. Mukherjee, and B. G. Martin, Developing key concepts in physics: Is it more effective to teach using scientific visualizations?, Teach. Sci. 58, 33 (2012).

[35] Y. J. Dori and J. Belcher, in Visualization in Science Education, edited by J. K. Gilbert (Springer, Dordrecht, 2005), pp. 187-216.

[36] A. Kohnle, C. Baily, and S. Ruby, arXiv:1410.0867.

[37] J. Trindade and C. Fiolhais, in Proceedings of the 3rd IEEE International Conference on Advanced Learning Technologies, 2003 (IEEE, New York, 2003) pp. 298-299.
[38] R. W. Bybee, J. C. Powell, and L. W. Trowbridge, Teaching Secondary Science: Strategies for Developing Scientific Literacy (Pearson, Upper Saddle River, NJ, 2008).

[39] M.P. Keating, Geometric, Physical, and Visual Optics (Butterworth-Heinemann, Boston, 2002).

[40] R. S. Worland and M. J. Moelter, Hands-on phasors and multiple-slit interference, Phys. Teach. 35, 486 (1997).

[41] M. D. M. Sánchez-López, I. Moreno, and A. MartínezGarcía, Education and Training in Optics and Photonics (Optical Society of America, Washington, DC, 2009) p. EMA1.

[42] F. Dorn and F. Bader, Physik-Gymnasium Sek II (Schroedel-Verlag, Hannover, 2010).

[43] H. D. Young and R. A. Freedman, Sears and Zemansky's University Physics with Modern Physics: Technology Update (Pearson Education, Harlow, Essex, 2014).

[44] I. A. Halloun, Modeling Theory in Science Education (Springer, Berlin, 2007).

[45] P. W. Zitzewitz, Glencoe Physics: Principles and Problems (McGraw-Hill, New York, 2005).

[46] D. Giancoli, Physics Principles with Applications (Pearson Education, Upper Saddle River, NJ, 2005).

[47] T. Duncan, Advanced Physics (Hodder Education, London, 2000).

[48] K. Johnson, S. Hewett, S. Holt, and J. Miller, Advanced Physics for You (Nelson Thornes, Cheltenham, 2000).

[49] D. Milošević, S. Dervišbegović, and Z. Šalaka, Physics with Solved Problems: For 3rd Year of Secondary School (Svjetlost, Sarajevo, 2000).

[50] R. Serway and J. Jewett, Physics for Scientists and Engineers with Modern Physics (Cengage Learning, Boston, MA, 2014).

[51] J. D. Cutnell and K. W. Johnson, Physics, 9th ed. (John Wiley and Sons, Hoboken, NJ, 2012).

[52] R. D. Knight, Physics for Scientists and Engineers: A Strategic Approach, 3rd ed. (Pearson Education, Upper Saddle River, NJ, 2013).

[53] D. Ary, L. C. Jacobs, C. Sorensen, and A. Razavieh, Introduction to Research in Education (Wadsworth Cengage, Belmont, CA, 2010).

[54] R. B. Johnson and L. Christensen, Educational Research: Quantitative, Qualitative, and Mixed Approaches (SAGE, Thousand Oaks, CA, 2012).

[55] M. Saghaei, http://mahmoodsaghaei.tripod.com/Softwares/ randalloc.html.

[56] J. Grehn and J. Krause, Metzler Physik SII (SchroedelVerlag, Hannover, 1998).

[57] See Supplemental Material at http://link.aps.org/ supplemental/10.1103/PhysRevPhysEducRes.12.010135 for a more detailed description of the implemented teaching approaches (Supplement A).

[58] See Supplemental Material at http://link.aps.org/ supplemental/10.1103/PhysRevPhysEducRes.12.010135 for accessing the Basic Wave Optics Survey (Supplement B).

[59] R. D. Sokoloff, Active Learning in Optics and Photonics Training Manual (UNESCO, Paris, 2006).

[60] W. J. Boone, J. R. Staver, and M. S. Yale, Rasch Analysis in the Human Sciences (Springer, Dordrecht, 2014).

[61] J. Rost, Lehrbuch Testtheorie, Testkonstruktion (Huber, Bern, 1996). 
[62] B. D. Wright and J. M. Linacre, Reasonable mean-square fit values, Rasch Measure. Trans. 8, 370 (1994).

[63] J. M. Linacre, A User's Guide to WINSTEPS: Rasch-Model Computer Program (MESA Press, Chicago, 2010).

[64] A. Bowling, in Handbook of Health Research Methods: Investigation, Measurement and Analysis, edited by A. Bowling and S. Ebrahim (Open University Press, Maidenhead, England, 2005), pp. 394-428.

[65] H.-J. Fisseni, Textbook of Psychological Diagnostics (Hogrefe-Verlag, Goettingen, 1997).

[66] R. J. Cohen and M. Swerdlik, Psychological Assessment: An Introduction to Tests and Measurements (McGraw-Hill Higher Education, Boston, 2009).
[67] D. Howell, Statistical Methods for Psychology (Cengage Learning, Belmont, CA, 2013).

[68] See Supplemental Material at http://link.aps.org/ supplemental/10.1103/PhysRevPhysEducRes.12.010135 for obtaining information about between-group differences on individual items (Supplement C).

[69] M. J. Strube, Small sample failure of random assignment: A further examination, J. Consult. Clin. Psychol. 59, 346 (1991).

[70] V. Mešić, Dž. Dervić, A. Gazibegović-Busuladžić, Dž. Salibašić, and N. Erceg, Comparing the impact of dynamic and static media on students' learning of one-dimensional kinematics, Eurasia J. Math. Sci. Technol. Educ. 11, 1119 (2015). 